\title{
The Relationship between Previous Lower Extremity Injury, Body Weight and Bilateral Eccentric Hamstring Strength Imbalance in Young Soccer Players
}

\author{
Anil Isık ${ }^{1}$, Gurcan Unlu², Omer Batin Gozubuyuk ${ }^{3}$, Turgay Aslanyurek ${ }^{1}$, Can Bereceli ${ }^{4}$
}

\begin{abstract}
Affiliations: 'Acibadem Sports, FIFA Medical Center of Excellence, Istanbul, Turkey, ${ }^{2}$ Middle East Technical University, Department of Physical Education and Sports, Ankara, Turkey, ${ }^{3}$ Istanbul University, Istanbul Medical Faculty, Department of Sports Medicine, Istanbul, Turkey, ${ }^{4}$ Besiktas Football Academy, Istanbul, Turkey
\end{abstract}

Correspondence: G. Unlu, Middle East Technical University, Department of Physical Education and Sports, 06800 Ankara, Turkey. E-mail: ugurcan@metu.edu.tr

ABSTRACT This study aims to investigate the effect of lower extremity (LE) injuries on bilateral hamstring eccentric strength imbalance (HSI) and to determine the relationship between body weight (BW) and HSI in young male soccer players. Eighty-eight young soccer players aged 14-19 in Turkey voluntarily participated in this study. Eccentric hamstring strength measurements were taken using a NordBord ${ }^{\oplus}$ Hamstring Testing Device. To obtain the LE backgrounds of the participants, individual interviews were administered to the players, and the obtained data were verified through a review of previous injury records. While $22(25 \%)$ out of 88 players reported LE injuries in the previous two years (injured players (IP)), the rest of them (75\%) did not report any LE injuries (non-injured players (NP)). HSI values as peak forces were computed by extracting the weaker leg values from the stronger leg values. Both the Analysis of Variance (ANOVA) and the Analysis of Covariance (ANCOVA) were performed, controlling the BW effect in order to test the effects of LE injuries on HSI. Correlation analysis was also conducted, taking into consideration the previous research findings on the relationship between body weight and strength variables. There was significant relationship between BW and HSI $((\mathrm{p}<0.05)(0.04>\mathrm{r}>0.02))$ and non-significant results for HSI $(\mathrm{F}(1.85)=0.578, \mathrm{p}>0.05)$. However, the effect of BW was significant for HSI $(\mathrm{F}(1.85)=3.91, \mathrm{p}<0.05, \eta 2=0.068)$. This study supported the hypothesis that hamstring muscle strength imbalance is not affected by lower extremity injuries and that body weight is a factor that may affect strength imbalance.

KEY WORDS hamstring strength imbalance, body weight, soccer injuries

$@$ MJSSMontenegro

STRENGTH IMBALANCE, BODY WEIGHT, AND INJURY RELATIONS

http://mjssm.me/?sekcija=article\&artid=159

\section{Introduction}

Lower extremity (LE) injury is one of the most common sport injuries among soccer players (Hägglund, Waldén, \& Ekstrand, 2013). Previous studies have shown that apart from internal factors such as age, gender, and being overweight, there are other factors, such as inflexibility, fatigue, shortened optimum muscle length, and strength imbalance, that may affect lower extremity injuries (Murphy, Connolly, \& Beynnon, 2003). Recent studies have focused on strength imbalance and fatigue as significant factors of sports injuries (Liu, Garrett, Moorman, \& Yu, 2012). Strength imbalance can be characterized by either side-to-side (right versus left) or front-to-back (agonist versus antagonist) differences in muscle length or strength. As a gold standard, isokinetic dynamometers have commonly been used over the years to measure strength and to assess muscle strength imbalance (Mijnarends et al., 2013), but these methods have some disadvantages, such as lack of portability and high cost of their widespread use (Opar, Piatkowski, Williams, \& Shield, 2013). To overcome these limitations, a number of testing systems have been developed. One of the most recent ones is the "Nordbord": a hamstring strength testing device devised by Opar et al. (2013). After a reliability study, they

Received: November 122017 | Accepted after revision: January 242018 | First published online: September 012018

() 2017 by the author(s). License MSA, Podgorica, Montenegro. This article is an open access article distributed under the terms and conditions of the Creative Commons Attribution (CC BY).

Conflict of interest: None declared. 
argued that this testing device provides the right information at the right time. Current studies on the validity of this claim have revealed that the Nordbord testing method is a reliable field-based alternative (Buchheit, Cholley, Nagel, \& Poulos, 2016).

The aims of this study were to examine the effect of previous lower extremity injuries (quadriceps and adductor muscle injuries) on hamstring eccentric strength imbalance and to determine the relationship between BW and hamstring eccentric strength imbalance using the Nordbord Nordic Hamstring Testing Device as the assessment tool. The majority of previous studies investigating the effects of strength imbalance on the risk of injury did not conduct follow-up about strength imbalance after repeated injuries. For this reason, it was not clearly underlined how sport injuries affect muscle imbalance ratios. Thus, this study aimed to examine the relationship between body weight (BW), muscle strength imbalance, and previous sports LE injuries.

\section{Methods}

Participants

This study consists of 88 young male soccer players who have played for first division teams in Turkey (U14, U15, U16, U17 and U19 teams). Prior to participation in the study, the players and their parents were informed of the possible risks of the study, and those who volunteered to participate gave their written informed consent. This study was approved by the Applied Ethics Research Center of the Middle East Technical University. The physical characteristics of the participants are presented in Table 1.

\begin{tabular}{|c|c|c|c|c|c|c|}
\hline \multirow[b]{2}{*}{ Variable } & \multicolumn{2}{|c|}{ LE injured ( $n=22)$} & \multicolumn{2}{|c|}{ LE non -injured ( $n=66)$} & \multicolumn{2}{|c|}{ Total $(n=88)$} \\
\hline & $M$ & SD & $M$ & SD & $M$ & SD \\
\hline Age (year) & 15.95 & 1.59 & 16.29 & 1.85 & 16.20 & 1.78 \\
\hline Height $(\mathrm{cm})$ & 171.32 & 6.42 & 174.67 & 8.82 & 173.83 & 8.38 \\
\hline Weight (kg) & 61.18 & 9.01 & 64.45 & 10.94 & 63.64 & 10.94 \\
\hline
\end{tabular}

To gather data from the participants whose characteristics are given in Table 1, two data parameters were utilized: previous LE injury status and Eccentric Knee Flexor-Strength Testing, the details of which are provided below.

\section{Previous Lower Extremity Injury Status}

In a semi-structured interview, the participants were asked what kind of injuries they had experienced in the previous two years, and their injury records were obtained to verify the interview data from the club clinician. Both the data obtained from the players through the interviews and the data gathered from the club clinician involved the information of injury type, injury location, grade (grade1-2-3) and the injured limb (right or left legs). In addition to hamstring injuries, quadriceps and adductor muscle injuries (grade1-2 strains) were also identified as lower extremity injuries if they prevented the player from participating in a match or training for a period of one week or more.

\section{Eccentric Knee-Flexor-Strength Testing}

Before the strength test, players' routine musculoskeletal and cardiovascular evaluations were conducted. After a standardized warm-up (5-minute cycling at submaximal intensity, a combination of skipping, high-knees and butt-kicking drills, 10 forward lunges per leg, 10 weight-free deep squats, 30 seconds of dynamic stretching per leg, and 2 Nordic hamstring movements with low resistance), participants performed one set of three maximal repetitions of bilateral Nordic hamstring exercises while using a NordBord ${ }^{\oplus}$ Hamstring Testing device (Qutbluebox, Queensland, AUS) as previously described (Opar et al., 2013). During the performance, the participants were encouraged to make maximal effort. All the participants performed one set of three maximal repetitions of the bilateral Nordic hamstring exercise, with the greatest force value $(\mathrm{N})$ used for the analysis.

\section{Data Preparation and Statistical Analyses}

To obtain strength imbalance values, side-to-side strength differences of hamstring eccentric strength value (Newton: N) were computed as follows:

$$
\text { HSI = Stronger Leg }(\mathrm{SL}) \text { value }- \text { Weaker leg }(\mathrm{WL}) \text { value }
$$

SPSS version 23 software was used for the statistical analysis. The 95\% level of confidence was used for all statistical tests. Descriptive statistics (means, standard deviations and frequencies) pertaining to the characteristics of the participants (age, body weight and height) were given. To verify the relationship between the selected BW and strength differences (peak torques and peak forces), Pearson correlation analysis was employed. Data analysis to obtain the effects of lower extremity injuries on muscle strength imbalance was divided into two parts. In the first part, one-way analysis of variance (ANOVA) was performed to determine the mean differences of hamstring eccentric strength imbalance between the injured and non-injured players. In the second part, analysis of covariance (ANCOVA) was executed. This was done to eliminate the effect of BW on the results. 
Results

In the current study, 22 out of 88 players (25\%) had previous lower extremity (LE) injuries in the previous 2 years (injured players - IP), and the rest of them (75\%) did not report any LE injuries (non-injured players $(\mathrm{NP}))$. The mean age $( \pm \mathrm{SD})$ of the participants was $16.20( \pm 1.78)$; the mean height was $173.83 \mathrm{~cm}( \pm 8.38)$, and the mean weight was $63.64 \mathrm{~kg}( \pm 10.94 \mathrm{~kg})$. Physical characteristics of participants are given in Table 1 . There were no significant differences between the parameters pertaining to the LE non-injured and LE injured players $(\mathrm{p}>0.05)$. Additionally, there were no significant average differences in HSI between the LE injured $(\mathrm{n}=22)$ and LE non-injured $(\mathrm{n}=66)$ players (Table 2$)$. HSI values as peak forces were computed by extracting weaker leg values from stronger leg values.

TABLE 2 Average mean $( \pm S D)$ values for Injured and non-injured players in maximum eccentric peak force $(\mathrm{N})$

\begin{tabular}{cccccc} 
& \multicolumn{2}{c}{ LE injured $(\mathbf{n}=\mathbf{2 2})$} & & \multicolumn{2}{c}{ LE non-injured $(\mathbf{n}=66)$} \\
\cline { 2 - 3 } \cline { 5 - 6 } Variable & $\mathbf{M}$ & SD & & $\mathbf{M}$ & \multicolumn{2}{c}{ SD } \\
\hline HSI & 43.73 & 31.04 & & 40.07 & 30.21 \\
\hline
\end{tabular}

Note: ${ }^{*} \mathrm{HSI}=$ Maximum eccentric peak force differences between legs

One-way analysis of variance (ANOVA) was performed to determine the effect of LE injuries on HSI; the ANOVA results demonstrated that the effect of the previous LE is not significant for HSI (F $(1.86)=0.239$, $\mathrm{p}>0.05, \eta 2=0.003)$. A Pearson correlation was performed to determine the relationship between BW and HSI (Figure 1), and a low ( $\mathrm{r}=0.2-0.4)$ correlation was observed between BW and HSI variables (Cohen, 1988).

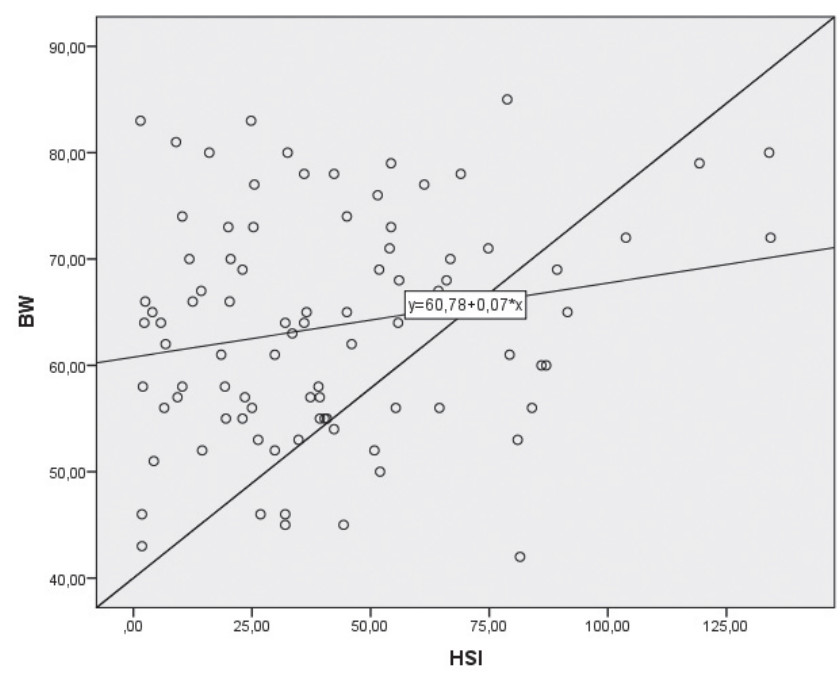

FIGURE 1 Correlation between BW and HSI in the total participants

In the literature, the possible effects of BW on strength parameters have been reported (Samson et al., 2000). In line with the literature, a positive correlation was found in this study between BW and HSI, which is a strength parameter; thus, the analysis continued with ANCOVA in the current study. A one-way ANCOVA was conducted to compare the effects of LE injury conditions (LE injured and non-injured) whilst controlling for BW. The results of ANCOVA indicated that although the BW effect was significant for HSI [F $(1.85)=3.91$, $\mathrm{p}<0.05 \eta 2=0.068$ ], there was no significant difference between groups with and without LE injury for HSI ( $F$ $(1.85)=0.578, \mathrm{p}>0.05)($ Table 3$)$.

\begin{tabular}{cccccc}
\multicolumn{7}{l}{ TABLE 3 Results of ANCOVA for the effect of LE injuries on HSI } & & & \\
\multicolumn{7}{c}{ SS } & df & MS & F & $\mathbf{\eta}^{\mathbf{2}}$ \\
\hline Injury Condition & 516.97 & 1 & 516.97 & 0.578 & .007 \\
BW & 3495.96 & 1 & 3495.96 & $3.91^{*}$ & .44 \\
Error & 76060.85 & 85 & 894.83 & & \\
Corrected Total & 227599.51 & 87 & & & \\
\hline
\end{tabular}

Note: BW of participant's as covariate; ${ }^{*} \mathrm{p}<.05$.

Most of the previous studies examined the effect of HSI on hamstring muscle strain rather than LE injury. However, in our study, as a part of LE, hamstring strain injury was also considered significant; thus, it was evaluated separately. A hamstring muscle strain was considered significant to the study separately. In this analysis, ANCOVA was computed to determine the effects of hamstring strain injury on HSI whilst LE injuries other than hamstring strain injuries were controlled together with BW. 


\begin{tabular}{|c|c|c|c|c|c|}
\hline & SS & df & MS & $\mathbf{F}$ & $\eta^{2}$ \\
\hline Hamstring Strain Injury ${ }^{\#}$ & 18.84 & 1 & 18.84 & 0.21 & .00 \\
\hline BW & 3332.21 & 1 & 3495.96 & $3.72^{*}$ & .42 \\
\hline LE injuries without $\mathrm{H}$ strains & 1263.38 & 1 & 1263.38 & 1.41 & 0.24 \\
\hline Error & 75272.39 & 84 & 896.1 & & \\
\hline Corrected Total & 29778.09 & 87 & & & \\
\hline
\end{tabular}

Note: ${ }^{*} \mathrm{p}<.05 . \mathrm{BW}=$ body weight (of participant's as covariate). $\mathrm{SS}=\mathrm{Sum}$ of Squares, $\mathrm{df}=$ degrees of freedom, MS= mean square, $\mathrm{F}=$ effect size, $\eta 2=$ eta-squared \#ten players suffered at least one hamstring strain injury and did not suffer any other LE injuries in the past two years.

Note: BW and other "LE injuries other than $\mathrm{H}$ strain injuries" are controlled

The findings pertaining to the effects of hamstring strain injuries on HSI revealed a non-significant relationship between hamstring strain injuries and HSI, as seen in Table 4. As in the ANCOVA results for the effect of LE injuries on HSI, the BW effect was significant $(\mathrm{p}<0.05)$ and the effect of hamstring strain injury on HSI by controlling BW and LE injuries other than hamstring strain injuries was not significant $(p>0.05)$.

\section{Discussion}

Many studies have examined the relationship between strength imbalance and sports injuries (Croisier, Ganteaume, Binet, Genty, \& Ferret, 2008; Grace, Sweetser, Nelson, Ydens, \& Skipper, 1984; Nadler, Malanga, DePrince, Stitik, \& Feinberg, 2000) and reported contradictory results. Some of these studies have revealed that bilateral strength imbalance has played a critical role in sports injury (Croisier, Forthomme, Namurois, Vanderthommen, \& Crielaard, 2002; Newton et al., 2006). Conversely, other studies have argued that there is no relationship between strength imbalance and injury occurrence (Bennell et al., 1998; Brockett, Morgan, \& Proske, 2004; Newton et al., 2006). The difference between the findings of the studies may be attributed to the differences in research design or to the influence of confounding variables. As a result, it remains unclear whether there is any effect of bilateral strength imbalance on sports injuries. Moreover, the previous studies did not investigate strength imbalance after injuries; thus, there is no evidence in the literature as to whether injuries cause imbalance or whether strength imbalance changes prior to injuries.

The present study aimed to focus on the effects of lower extremity injuries on strength imbalance rather than the effect of strength imbalance on any injury mechanism. The majority of the previous studies investigating the association between strength imbalance and sports injury did not consider in their analysis the role of other potentially significant factors, such as age, gender, body weight and previous injury status. In the statistical analysis of this study, the possible effects of body weight (due to increased muscle mass), which is one of the significant factors for strength, was also considered. It is clearly known that an increase in body weight is due to increased muscle mass or total body fat. In this respect, this study aimed to reveal more comprehensive statistical results.

Body weight (due to increased muscle mass) is one of the major determinants affecting muscular strength (Hasan, Kamal, \& Hussein, 2016). Buchheit et al., (2016) have indicated the effect of body weight on eccentric peak torques in the soccer players using the Nordbord testing device and they developed a regression model to estimate players' expected strength taking their body weight into account. In light of that study and the present study, it can be said that it is appropriate to consider the effects of body weight on strength imbalance in further studies.

Bilateral strength imbalance can be calculated as side-to-side strength difference or the ratio of right and left limbs or between stronger and weaker limbs. It was stated in the literature that using ratios has some disadvantages (Impellizzeri, Bizzini, Rampinini, Cereda, \& Maffiuletti, 2008). In this study, instead of ratios, side-to-side strength differences were preferred to obtain strength imbalance values. Nadler et al., (2000) evaluated side-to-side strength differences in their participants' abductor and extensor muscles to obtain strength imbalance data. They have indicated that there were no significant differences between athletes with and without reported lower extremity injuries in terms of strength imbalance (side-to-side strength differences of abductors or extensors) considering the participant's body weight. In a similar way, absolute strength difference values between legs were calculated to utilize the strength imbalance values in this study.

In the study of Yamamoto, (1993), which is one of the first studies on the effect of HSI on injuries, the players who reported hamstring strain injuries in the previous two years had more strength imbalance of the bilateral legs in comparison to the players who reported no hamstring strain injuries. More recently, Bourne, Opar, Williams and Shield, (2015) found that eccentric knee-flexor strength and previous hamstring strain injury are linked with an increased risk of future hamstring strain injury. Many other studies have also demonstrated that bilateral strength imbalance may be related to the occurrence of hamstring strain injury (Cameron, Adams, \& Maher, 2003; Yeung, Suen, \& Yeung, 2009). Contrary to the previous findings in elite soccer, bilateral strength imbalance was not associated with lower extremity injuries in the current study. Our 
findings corroborate the results of some previous studies indicating that bilateral strength imbalance is not associated with the incidence of sports injury (Bennell et al., 1998; Opar et al., 2014; Zvijac, Toriscelli, Merrick, \& Kiebzak, 2013). Zvijac et al. (2013) found recently that there is no relationship between knee concentric strength imbalance and hamstring strain injury. Nadler et al. (2000) reported that there is no significant side-to-side percentage difference of the gluteus maximus strength between athletes with and without lower extremity injury. Our findings are consistent with these reports and do not support prior hamstring injuries as a risk factor for re-injury.

\section{Conclusion}

In this study, young soccer players with reported lower extremity injuries in the previous two years had similar eccentric hamstring strength imbalance in comparison to non-injured soccer players. While many studies have indicated hamstring strength imbalance as a risk factor for lower extremity injury especially in the hamstring, several other studies have reported contrary findings. The finding of this study supported the null hypothesis that hamstring muscle strength imbalance is not affected by either lower extremity injuries or hamstring strain injuries and that body weight is a factor affecting strength imbalance. Future studies are needed to better understand the relationship between the risk of sport injury and strength imbalance considering multiple factors such as body weight, muscle flexibility and age.

There are some limitations that should be acknowledged. Firstly, the measurement of strength and assessment of imbalance were only performed at a single time point after the injuries. It is important to consider that strength may change over time and a pre-test /post-test experimental design in which participant's strength is measured twice, once before and after a period may lead to more robust inferences. To eliminate the effect of body weight, previous studies generally have utilized relative strength values (Nadler et al., 2000). Rather than using relative strength values, the body weight effect was controlled using ANCOVA analysis in the present study. Although body weight mainly has positive effects on strength, it can also have negative effects depending on the body fat percentage. The body weight percentage of participants was not measured in this study. It was not possible to obtain homogeneous groups regarding body weight or body mass index as consequences of the age range factor in the population of this study. Stratified random sampling can be used to obtain more homogeneous groups for further studies.

\section{REFERENCES}

Bennell, K., Wajswelner, H., Lew, P., Schall-Riaucour, A., Leslie, S., Plant, D., \& Cirone, J. (1998). Isokinetic strength testing does not predict hamstring injury in Australian Rules footballers. British Journal of Sports Medicine, 32(4), 309-314.

Bourne, M. N., Opar, D. A., Williams, M. D., \& Shield, A. J. (2015). Eccentric knee flexor strength and risk of hamstring injuries in rugby union: a prospective study. The American Journal of Sports Medicine, 43(11), 2663-2670.

Brockett, C. L., Morgan, D. L., \& Proske, U. W. E. (2004). Predicting hamstring strain injury in elite athletes. Medicine \& Science in Sports \& Exercise, 36(3), 379-387.

Buchheit, M., Cholley, Y., Nagel, M., \& Poulos, N. (2016). The Effect of Body Mass on Eccentric Knee-Flexor Strength Assessed With an Instrumented Nordic Hamstring Device (Nordbord) in Football Players. International Journal of Sports Physiology and Performance, 11(6), 721-726.

Cameron, M., Adams, R., \& Maher, C. (2003). Motor control and strength as predictors of hamstring injury in elite players of Australian football. Physical Therapy in Sport, 4(4), 159-166.

Cohen, J. (1988). Statistical power analysis for the behavioral sciences Lawrence Earlbaum Associates. Hillsdale, NJ, 20-26.

Croisier, J.-L., Forthomme, B., Namurois, M.-H., Vanderthommen, M., \& Crielaard, J.-M. (2002). Hamstring muscle strain recurrence and strength performance disorders. The American Journal of Sports Medicine, 30(2), 199-203.

Croisier, J.-L., Ganteaume, S., Binet, J., Genty, M., \& Ferret, J.-M. (2008). Strength imbalances and prevention of hamstring injury in professional soccer players a prospective study. The American Journal of Sports Medicine, 36(8), 1469-1475.

Grace, T. G., Sweetser, E. R., Nelson, M. A., Ydens, L. R., \& Skipper, B. J. (1984). Isokinetic muscle imbalance and knee-joint injuries. A prospective blind study. J Bone Joint Surg Am, 66(5), 734-740.

Hägglund, M., Waldén, M., \& Ekstrand, J. (2013). Risk factors for lower extremity muscle injury in professional soccer: the UEFA Injury Study. The American Journal of Sports Medicine, 41(2), 327-335.

Hasan, N. A. K. A. K., Kamal, H. M., \& Hussein, Z. A. (2016). Relation between body mass index percentile and muscle strength and endurance. Egyptian Journal of Medical Human Genetics, 17(4), 367-372.

Impellizzeri, F. M., Bizzini, M., Rampinini, E., Cereda, F., \& Maffiuletti, N. A. (2008). Reliability of isokinetic strength imbalance ratios measured using the Cybex NORM dynamometer. Clinical Physiology and Functional Imaging, 28(2), 113-119.

Liu, H., Garrett, W. E., Moorman, C. T., \& Yu, B. (2012). Injury rate, mechanism, and risk factors of hamstring strain injuries in sports: A review of the literature. Journal of Sport and Health Science, 1(2), 92-101.

Mijnarends, D. M., Meijers, J. M. M., Halfens, R. J. G., ter Borg, S., Luiking, Y. C., Verlaan, S., ... Schols, J. M. G. A. (2013). Validity and reliability of tools to measure muscle mass, strength, and physical performance 
in community-dwelling older people: a systematic review. Journal of the American Medical Directors Association, 14(3), 170-178.

Murphy, D. F., Connolly, D. A. J., \& Beynnon, B. D. (2003). Risk factors for lower extremity injury: a review of the literature. British Journal of Sports Medicine, 37(1), 13-29.

Nadler, S. F., Malanga, G. A., DePrince, M., Stitik, T. P., \& Feinberg, J. H. (2000). The relationship between lower extremity injury, low back pain, and hip muscle strength in male and female collegiate athletes. Clinical Journal of Sport Medicine, 10(2), 89-97.

Newton, R. U., Gerber, A., Nimphius, S., Shim, J. K., Doan, B. K., Robertson, M., ... Kraemer, W. J. (2006). Determination of functional strength imbalance of the lower extremities. The Journal of Strength \& Conditioning Research, 20(4), 971-977.

Opar, D. A., Piatkowski, T., Williams, M. D., \& Shield, A. J. (2013). A novel device using the Nordic hamstring exercise to assess eccentric knee flexor strength: a reliability and retrospective injury study. Journal of Orthopaedic \& Sports Physical Therapy, 43(9), 636-640.

Opar, D. A., Williams, M., Timmins, R., Hickey, J., Duhig, S., \& Shield, A. (2014). Eccentric hamstring strength and hamstring injury risk in Australian footballers. Medicine \& Science in Sports \& Exercise, 46.

Samson, M. M., Meeuwsen, I. B., Crowe, A., Dessens, J. A., Duursma, S. A., \& Verhaar, H. J. (2000). Relationships between physical performance measures, age, height and body weight in healthy adults. Age and Ageing, 29(3), 235-242.

Yamamoto, T. (1993). Relationship between hamstring strains and leg muscle strength. A follow-up study of collegiate track and field athletes. The Journal of Sports Medicine and Physical Fitness, 33(2), 194-199.

Yeung, S. S., Suen, A. M. Y., \& Yeung, E. W. (2009). A prospective cohort study of hamstring injuries in competitive sprinters: preseason muscle imbalance as a possible risk factor. British Journal of Sports Medicine, 43(8), 589-594.

Zvijac, J. E., Toriscelli, T. A., Merrick, S., \& Kiebzak, G. M. (2013). Isokinetic concentric quadriceps and hamstring strength variables from the NFL Scouting Combine are not predictive of hamstring injury in first-year professional football players. The American Journal of Sports Medicine, 41(7), 1511-1518. 